\title{
Impact of Wind Generation Location on Power System Losses
}

\author{
I.S.Naser \\ Department of Renewable Energy, College of Mining and Energy, Sebha University, Libya \\ DOI: https://doi.org/10.21467/proceedings.2.25 \\ * Corresponding author email: ibr.naser@sebhau.edu.ly
}

\begin{abstract}
The global environmental and renewable energy initiatives have led to an increased connection of wind generation to the electricity power networks, the increase in wind generation makes a significant impact on the power system and planning for both customers and electricity suppliers. This paper investigates the impact of wind generation location in power system losses when connected at the transmission network. The doubly-fed induction generator (DFIG) and different connection scenarios are used to investigate the impact. Finally, some conclusions that provide a better understanding of the behavior of wind generator when connected to strong bus or weak bus. The Power World Simulator is used to obtain simulated results.
\end{abstract}

Keywords: Wind generation, DFIG, Transmission network, Real system losses.

\section{Introduction}

The increasing interest in producing electricity using renewable resources is growing rapidly due to ability of these resources to reduce greenhouse gases [1]. In some remote areas economic factor could be a major one. One of the most prevalent and desirable technologies is wind power. Wind power has been dramatic development throughout the World especially, connected to both distribution and transmission system. Recently wind generator have been experiencing a rapid development and the size of wind turbines and wind farms are increasing, and the impact of wind generation on power system operation is more important [2]. The pattern and size of the wind turbine and generator is based on the wind characteristics. Wind generation can be divided into several types depending on the design of the rotor and generator, and wind generation can be a resource for both active and reactive power. Wind turbine generators can be modelled into two categories: a fixed speed with induction generator, and a variable speed generator in PQ or PV mode.

In general, increased wind penetration level will have the impacts on the operation of the system, and the effect is becoming increasing. These impacts could be positive or negative depend on a number of factors, including wind power penetration level, type wind generator, geographical dispersion of wind generation and the size of the electrical networks [3]. Connecting a wind generator to a network can have negative effects, such as a new loading

(C) 2018 Copyright held by the author(s). Published by AIJR Publisher in Proceedings of First Conference for Engineering
Sciences and Technology (CEST-2018), September 25-27, 2018, vol. 1 .
This is an open access article under Creative Commons Attribution-NonCommercial 4.0 International (CC BY-NC 4.0)
license, which permits any non-commercial use, distribution, adaptation, and reproduction in any medium, as long as the
original work is properly cited. ISBN: 978-81-936820-5-0
original work is properly cited. ISBN: $978-81-936820-5-0$ 
Impact of Wind Generation Location on Power System Losses

situation and changed power flow direction. Integration of a wind farm into a network can also affect the power losses and stability of the system [4]. The impact of wind generation on the distribution system has been studied and. it show that wind generation integrated on the distribution system can improve overall system voltage profile and at the same time system losses are reduced [5-6].

The objective of this paper is to investigate the impact of DFIG location based wind generation on system MWh losses in transmission system. The IEEE 30-bus system is used as a test case, simulated using the Power World Simulator, and wind penetration level is varied from $20 \%$ to $30 \%$ to assess the impact on power system MWh losses. For the studies carried out in this paper, only focus on variable speed unit (DFIG) and modelled as PV bus, this farm is operated from $0.95 \mathrm{PF}$ for $\mathrm{Q}_{\max }$ and $0.95 \mathrm{PF}$ for $\mathrm{Q}_{\min }$.

\section{Doubly Fed Induction Generator}

This configuration consists of a wound rotor induction generator where the stator windings are directly connected to the grid and the rotor windings are connected to a back-to-back power converter. This back-to-back power converter is dimensioned for partial generator power and is able to operate bi-directionally. It uses a wound rotor induction generator with slip rings to take current into or out of the rotor winding, and variable speed operation is obtained by injecting the controllable voltage into the generator rotor at slip frequency [7].

As shown in Figure 1 the rotor winding is fed through the variable frequency power converter, typically based on two AC/DC insulated gate bipolar transistor (IGBT) based voltage source converters (VSC) linked by the DC bus. The power converter decouples the network electrical frequency from the rotor mechanical frequency, enabling the variable speed operation of the wind turbine. The voltage source converter (VSC) produces an AC voltage that is controllable in magnitude and phase, similar to the synchronous generator or synchronous compensator. The VSC commutates independently of the AC-side voltage and consequently it can be used on the load-only system. This makes the VSC useful for rotor connection, wind farm connection and so forth. Converters (C1) and (C2) in Figure 1 are used to control the doubly fed induction generator wind turbine. A number of manufacturers use converter (C1) to provide torque/speed control, together with terminal voltage or power factor control for the overall system. Converter (C2) is used to maintain the DC link voltage and provide the path for power to flow to and from the $\mathrm{AC}$ system at unity power factor.

ISBN: 978-81-936820-5-0 


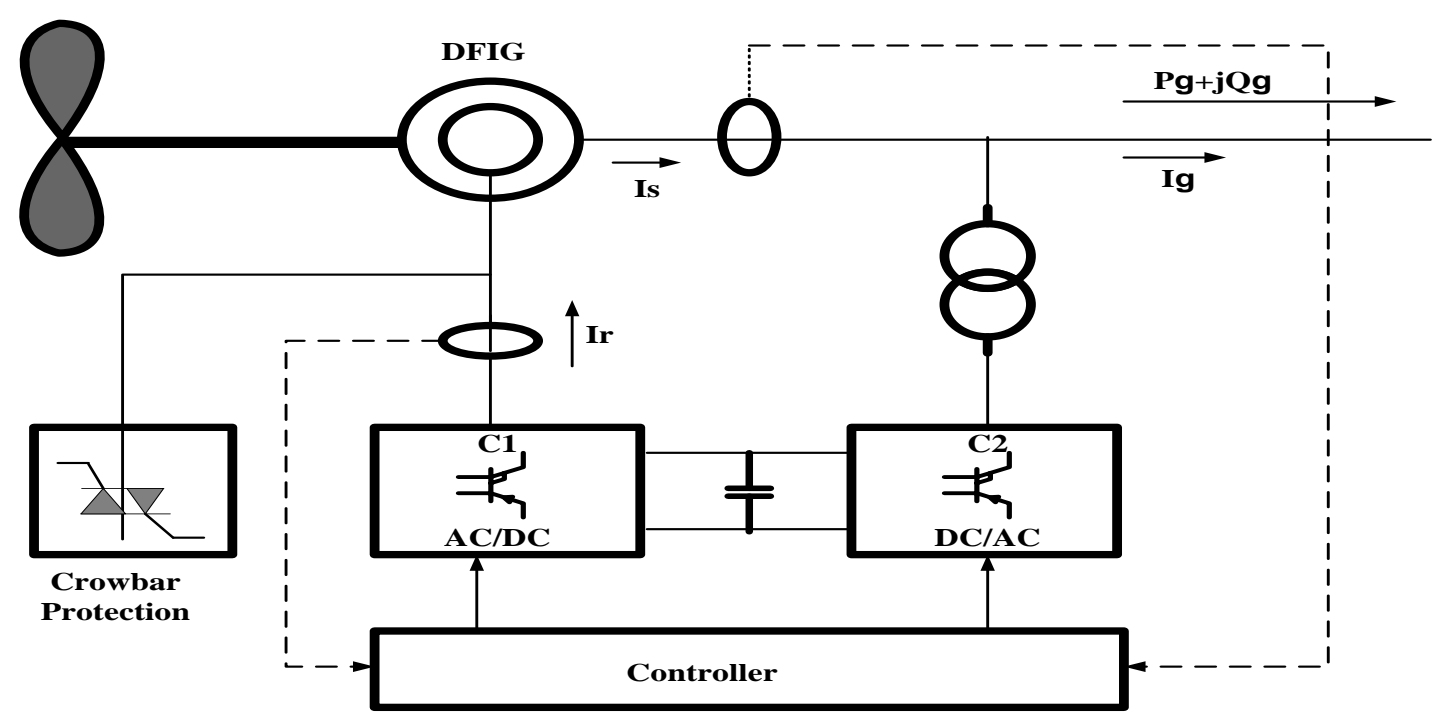

Figure 1: Typical configuration of the DFIG wind turbine

\section{Doubly Fed Induction Generator Model.}

Recent grid codes demand from wind farms to provide reactive output regulation, often in response to power system voltage, much as the conventional power generations. Manufacturers offer different options for var generation by DFIG based wind turbines in steady state operation. The reactive power requirements are related to the characteristics of each network. DFIG can be modelled in load flow studies as PQ or PV buses, so as to operate in power factor controlled or voltage controlled modes [8]. When the DFIG is modelled as a PQ bus, the DFIG is usually employed as a unity power factor (P.F) operation (zero reactive power output) though other (P.F) values can be specified (e.g, from 0.95 leading to 0.95 lagging). In voltage controlled mode, the DFIG is modelled as PV bus with Q limits applied. In this mode, a stator $\mathrm{Q}$ is varied to maintain the voltage at the point of common coupling within given reference values (in this case voltage is controlled at $1.0 \mathrm{p.u}$ ). For the studies carried out in this paper, only focus on variable speed unit (DFIG) and modelled as PV bus.

\section{$4 \quad$ Test system and simulation results}

A modified IEEE30-bus is modelled in Power World Simulator and it used as the test system [9]. The test system consists of six generators which supply power to twenty one loads through $132 / 33 \mathrm{kV}$ substation, the modified test system is analysed using optimal power flow (OPF).

Proceedings of First Conference for Engineering Sciences and Technology (CEST-2018), vol. 1 
Impact of Wind Generation Location on Power System Losses

Wind farms are connected at different buses at different penetration levels of wind generation with different scenarios. For the studies carried out in this paper, only focus on variable speed unit (DFIG) and modelled as PV bus. A single-line diagram of IEEE-30 bus system is shown in Figure 2.

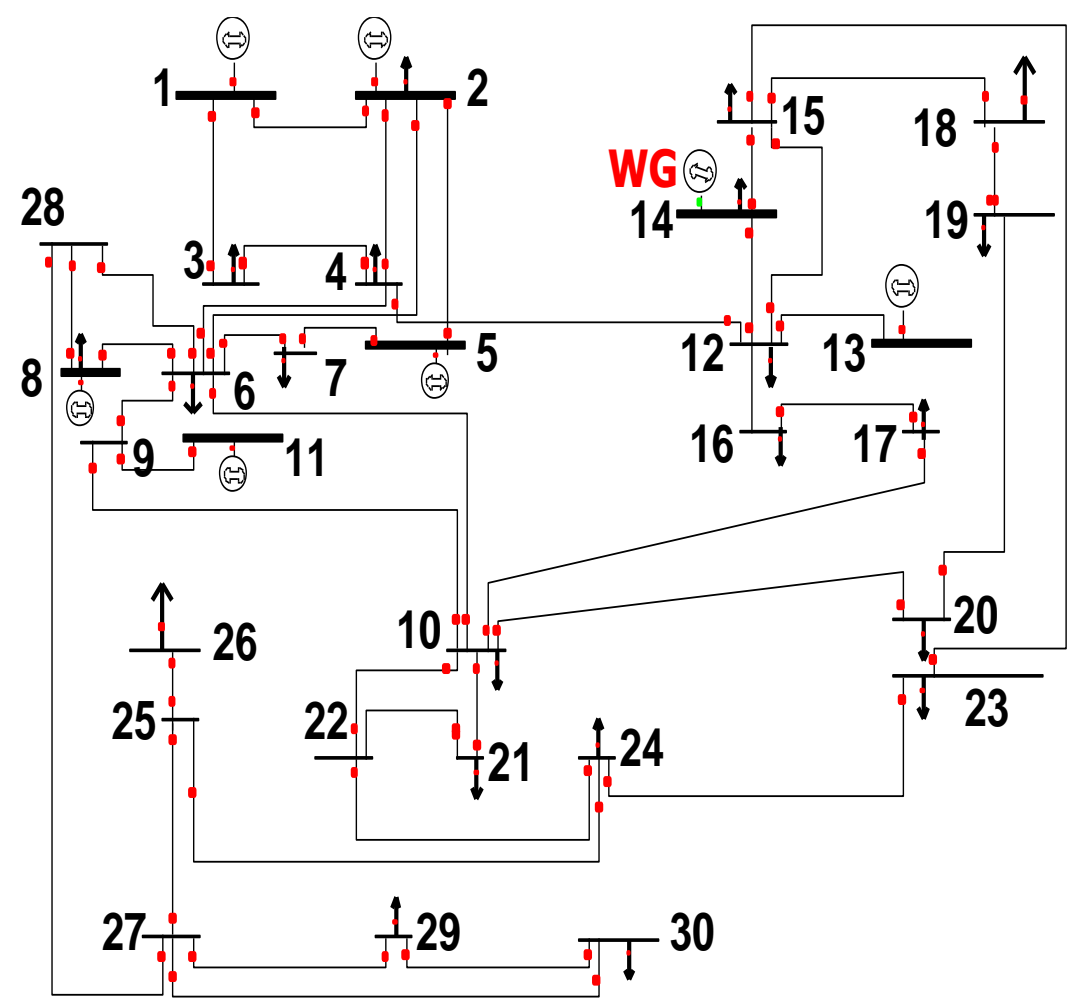

Figure 2: The modified IEEE-30 bus test system

An analysis method is used to assess a system loss that considers the time varying characteristics of the power system generation components, penetration level of wind generation, and the variable nature of wind power, using the time step option in the Power World Simulator. The analysis method has three major inputs. The wind power input is the time series values of the wind generation connected to the network in MW at one hour intervals. These data were obtained from a utility operating in the United Kingdom from a wind farm for a one day period and at one hour intervals. Table 1 shows the wind power input data for $20 \%$ and $30 \%$ penetration levels with a one day load period [10]. The input of the conventional generators is their availability considering their capacity and quantity, while the load model input is the forecasted load profile applied to the network for the evaluation of system losses. 
Table 1: Wind power input data for different wind penetration with one day load period

\begin{tabular}{|c|c|c|c|}
\hline $\begin{array}{c}\text { Time } \\
\text { (Hour) }\end{array}$ & $\begin{array}{c}\text { Total Loads } \\
\text { (MW) }\end{array}$ & $\begin{array}{c}20 \% \mathrm{WP} \\
(200 \mathrm{MW})\end{array}$ & $\begin{array}{c}30 \% \mathrm{WP} \\
(300 \mathrm{MW})\end{array}$ \\
\hline 01:00:00 & 283.4 & 24.96 & 55.5 \\
02:00:00 & 283.4 & 57.7 & 37 \\
03:00:00 & 302.5 & 174.5 & 100.5 \\
04:00:00 & 302.5 & 162.4 & 8 \\
05:00:00 & 358.8 & 104.3 & 91 \\
06:00:00 & 358.8 & 45.6 & 275.5 \\
07:00:00 & 500 & 119.4 & 165.2 \\
08:00:00 & 500 & 190.2 & 5.5 \\
09:00:00 & 615.5 & 164.4 & 35.7 \\
10:00:00 & 615.5 & 143.4 & 167.4 \\
11:00:00 & 454.6 & 84.7 & 15.3 \\
12:00:00 & 454.6 & 54.2 & 110.5 \\
13:00:00 & 504.3 & 97.9 & 80.7 \\
14:00:00 & 504.3 & 200 & 12.5 \\
15:00:00 & 745.5 & 157 & 6.5 \\
16:00:00 & 745.5 & 123.2 & 285.7 \\
17:00:00 & 850.1 & 200 & 300 \\
18:00:00 & 850.1 & 96.4 & 7.5 \\
19:00:00 & 695 & 130.5 & 0 \\
20:00:00 & 695 & 38.2 & 12.4 \\
21:00:00 & 450 & 13.5 & 113.6 \\
22:00:00 & 450 & 43.8 & 35.9 \\
23:00:00 & 314.9 & 30.2 & \\
00:00:00 & 314.9 & 70.1 & \\
\hline & & & \\
\hline
\end{tabular}

The objective of connecting wind generation at different locations is to investigate the effect of location site on the total system MWh losses. There are three wind farm connection scenarios: a strong area at bus 28 (case 1), a weak area at bus 14 (case 2), and two locations at buses 6 and 28 as dispersion of wind generation (case3). The total system MWh losses are analysed for two different wind generation levels (20\% and 30\%). The results presented here are for a 24 hour period. The total system MWh losses of the network are calculated for every one hour of the simulation and are recorded. As shown in Figure 3, the value of the total system MW losses decrease with the connection of wind generation from 149.48 MW at the

Proceedings of First Conference for Engineering Sciences and Technology (CEST-2018), vol. 1 
Impact of Wind Generation Location on Power System Losses

peak load period in the case of no wind generation to 80.06 MW for the connection case 1 ( one wind farm is connected to a strong bus 28), 84.89 MW for the connection case 3 ( two wind farms are connected to buses 6 and 28) and 129.6 MW as one wind farm is connected to a weak bus 14 when the percentage of wind capacity was 20\% (200 MW). It can be seen that for $20 \%$ wind penetration level, the total system real power losses are reduced significantly for both wind connection scenarios compared to the base case. From a total system real power loss point of view, a single wind farm being connected to a strong bus is a better option and will reduce the total real power losses more than other connection scenarios.

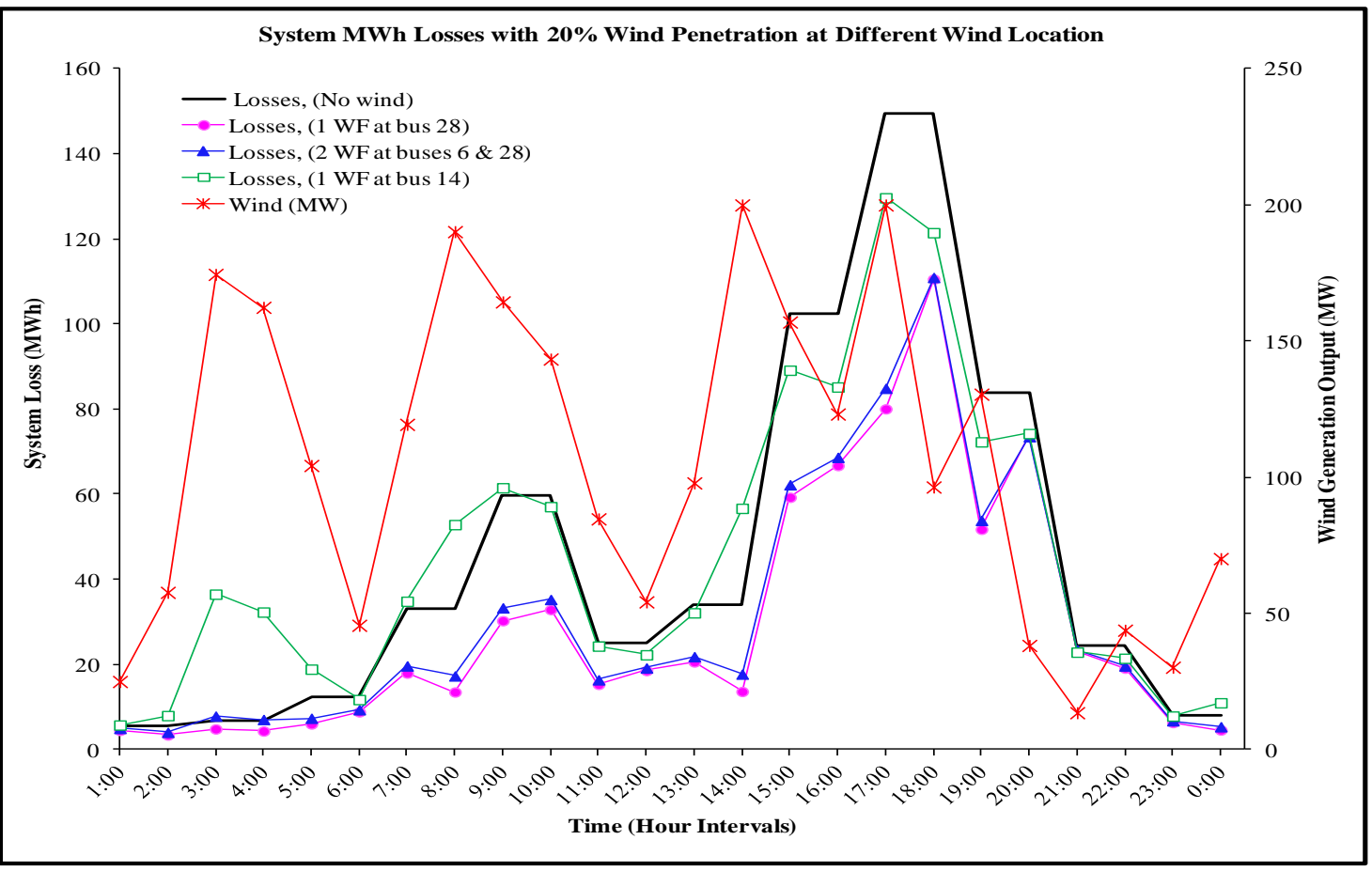

Figure 3: The total system MWh losses of IEEE-30 bus system with $20 \%$ wind penetration level, when wind farm is connected to the network at different connection scenarios.

When the wind penetration level increases from 20\% to 30\%, the total system MW losses are reduced more for both wind connection scenarios (for one strong location and for multiple locations) compared to the base case and when the wind generation is 30\% (300 MW). The system MW losses are recorded as $59.4 \mathrm{MW}$ when the wind farm is connected to the strong bus and $62 \mathrm{MW}$ for 2 wind locations. The system witnesses a significant reduction in system MW losses for higher wind penetration levels as the system becomes more heavily loaded, as shown in Figure 4. However, when the wind penetration level, connected to weak bus 14, increases to $30 \%$, the total system MW losses are increased to $166.1 \mathrm{MW}$, which is a slight 
increase compared to the no wind case (149.48 MW). This means that a higher wind penetration might increase the total system MW losses during system load ability (at the peak load) when the wind farm is connected to a weak area.

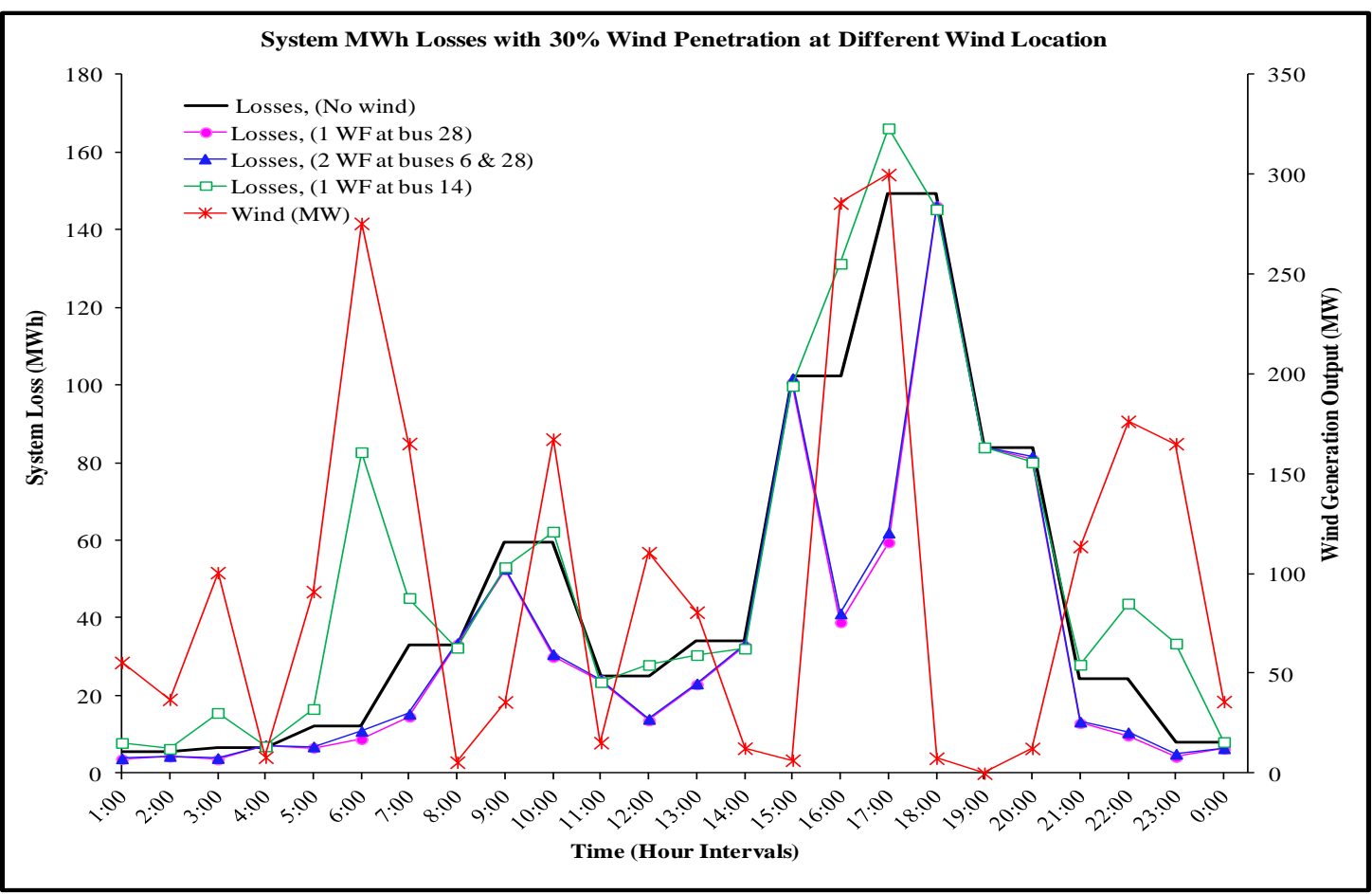

Figure 4: the total system MWh losses of IEEE-30 bus system with $30 \%$ wind penetration level, when wind farm is connected to the network at different connection scenarios.

\section{Conclusions}

This paper has investigated the impact of wind generation location on the total system MW losses based on system load ability in the transmission network. A DFIG based wind farm with a voltage controlled mode was integrated into an IEEE-30 bus system. Different connection scenarios of wind farms were considered; a single location (a strong bus and a weak bus) and dispersion of wind farms in two locations. Different penetration levels of wind generations were used. The results show that a single strong location for a wind farm with higher wind penetration levels can achieve a significant reduction in the total system MW losses when the system loading is high. However, the results show that total real power losses increase if the wind farm is located at a weak area with higher wind penetration levels when the system is highly loaded. 
Impact of Wind Generation Location on Power System Losses

\section{References}

[1] Federico Milano, "Assessing adequate voltage stability analysis tools for networks with high wind power penetration," IEEE DRPT Conference, 6-9 April 2008, Nanjing, China, pp.2492-2497

[2] I.S.Naser, M.A.Alsharif, MN.Hussin, M.A. Alrmah "Evaluating the impact of wind generation on transmission network power losses", LICEET 2018, Libya

[3] I.S. Naser, Olimpo Anaya-Lara, K. L. Lo, "Study of the Impact of Wind Generation on Voltage Stability in Transmission Networks," IEEE DRPT, The 4th International Conference on Electric Utility Deregulation and Restructuring and Power Technologies. 6th-9th July, 2011, Shandong, China

[4] L. T. Ha, T. K. Saha, "Investigation of Power Loss and Voltage Stability Limits for Large Wind Farm Connections to a Subtransmission Network", IEEE Power Engineering Society General Meeting, Colorado, USA, June 2004.

[5] A. P. Agalgaonkar, S.V. Kulkarni, S. A. Khaparde, "Impact of Wind Generation on Losses and Voltage Profile in a Distribution System”, 86 Conference on Convergent Technologies for Asia-Pacific Region, TENCON 2003, Vol. 2, pp.775-779.

[6] K.C Divya, P. S. Nagendra Rao, "Models for Wind Turbine Generating Systems and Their Application in Load Flow Studies", ELSEVIER, Electric Power Systems Research Vol. 76, 2006, pp. 844-856.

[7] L. Holdsworth, X. G. Wu, J. R. Ekanayake, N. Jenkins, "Comparison of Fixed-Speed and Doubly-Fed Induction Wind Turbine during Disturbances”, IEE Proceedings Part C, 150 (3), pp.343-352, 2003.

[8] A. N. R. Ullah, T. Thiringer, "Variable Speed Wind Turbines for Power System Stability Enhancement", IEEE Transactions on Energy Conversion, Vol. 22, No. 1, pp. 52-60, March 2007.

[9] "Power Systems Test Case Archive" available from: http://www.ee.washington.edu/research/pstca/

[10] UKGDS, "United Kingdom Generic Distribution System" 2009, available from: http://www.sedg.ac.uk/UKGDS Networks. pdf. 